\title{
Can the Generalist Survive the 21st Century?
}

Internal medicine and family practice are siblings whose common parent is general practice. Like many other siblings, their relationships have not always been amicable. But as the new century dawns, they promise to be drawn together by the threats to the generalist function, which is crucial to the identities of both specialties.

In some ways, internal medicine and family practice are conceptual paradoxes. Both were born to counter the growing power of the specialties; both distanced themselves from general practice because it was too all-encompassing; both proclaimed the indispensability of the generalist. Yet both also became specialties with their own boards, examinations, professional associations, and academic departments.

Their similarities notwithstanding, family medicine and internal medicine have yet to relate to each other in a synergistic way that would protect them against the erosive forces acting on the generalist function, which is at the heart of each. Without succumbing to the current epidemic of millennial prophesying, some reflections on the need for cooperative survival are in order.

Internal medicine was the first to separate itself from general practice. Its conceptual birth was signaled in William Osler's address to the New York Academy of Medicine in 1897. Osler sketched in a grand vision of the internist, who, he said, "... could never be a specialist." Osler's definition of internal medicine confined it to the nonsurgical disease of adults, exclusive of those peculiar to women. Osler's generalist was to be the product of 40 years of maturation in the clinic laboratory and library.

Until World War II, it was still possible to be an across-the-board consultant, scholar, clinician, and

Submitted, revised, 23 December 1999.

From the Center for Clinical Bioethics, Georgetown University Medical Center, Washington, DC. Dr. Pellegrino is the John Carroll Professor of Medicine and Medical Ethics. Address reprint requests to Edmund D. Pellegrino, MD, Center for Clinical Bioethics, Georgetown University Medical Center, 4000 Reservoir Road, NW, \#D-238, Washington, DC 20007. diagnostician on the Oslerian model. But in the postwar years, medical knowledge and techniques expanded exponentially. Specialties multiplied and became more technical and more recondite. General internists realized they could no longer honestly provide the level of clinical sophistication the subspecialists made available. For a time, some became general internists with a special interest in one of the specialties. When, for similar reasons, this, too, became untenable, internists simply became general internists. Patients and general practitioners quickly recognized all this and increasingly sought consultations directly from the relevant specialists.

General internists then began to assume a role as personal physician - as a provider of continuing comprehensive care and a synthesizer, as well as the coordinator and interpreter, of specialists' recommendations. Almost concurrently, health policy and economics underscored the need for primary care, and internal medicine joined general practice, family practice, pediatrics, and even obstetrics and gynecology in this category.

Today, under the pressure of managed care, the internist has become primarily a first-contact physician, a gatekeeper against overuse of specialists and tests. With the 15 minutes or so allotted to each patient, and with financial penalties for underproductivity, the things that once distinguished the general internist-in-depth analysis of the patient's problems through a thorough history and physical examination, continuity, comprehensiveness, personal care, etc-had to be compromised. Only those few internists in private practice who could afford to stay out of the managed care plans could hold onto remnants of the internists' ideal.

Now, the general internist is confronted by a new kind of generalist, the hospitalist with his or her own set of ethical issues. ${ }^{2}$ Having been replaced earlier by the intensivist and the emergency care physician, the generalist is about to be further displaced from the hospital. What is left is a role in primary care coming ever closer to family medicine but without the familial orientation or the better 
training of the family physician in such things as minor trauma, office gynecology, and so on.

Up until now, the path of family medicine has been somewhat less troubled. Like internal medicine, general practice flourished in the two decades preceding World War II. After that war, general practice suffered a decline for a variety of reasons -the prestige of the specialists, their better remuneration and work conditions, the absence of academic departments and residencies in family medicine, the decline in the number of general practitioners doing surgery, the flight from rural to urban practice, among others.

But, as the number of general practitioners decreased, the public need and demand for firstcontact, family-oriented practitioners increased enormously. In 1966, four national reports recommended the formation of a new specialty. In 1969, the American Board of Family Practice was born. Under this impetus, family practice acquired academic stature, a leading place in primary care, and a central position of importance in managed care. The generalist, again, became a specialist but in a much broader field. ${ }^{3}$

As we enter the 21 st century, the generalist in managed care and primary care is the family physician and the general internist. The generalist in the hospital promises to be the hospitalist and the intensivist. The consultant general internist, as envisioned by Osler and his later transformations into the personal physician, is already almost extinct. He survives only among well-to-do patients who can afford to consult private practice internists who have stayed out of managed care plans and have the privilege of an orderly, careful evaluation of their patients' needs. Even there, however, the idea of the generalist has become attenuated. The number of consultations they require expands daily. Even the best internists attend their patients less frequently in the hospital. Other members of the health care team often subsume their nontechnical functions. Imaging techniques often replace their diagnostic skills.

Thus far, family practice has fared somewhat better than internal medicine in the managed care milieu, but this cannot last into the next century. Managed care is posited on cost-containment and on making a profit in a competitive marketplace. Family physicians who try to fulfill the aims of their specialty-providing preventive, primary, continuing, comprehensive, psychosocially oriented family health for individuals and families-are headed for increasing restriction on their attempts to be generalists. Personal attention, continuity, and attending to family dynamics require the physician's time, which is the most severely rationed resource in managed care. So does true preventive medicine, which depends on behavior modification. Triage, episodic care, the quick prescription, and high volume are the payoff criteria. Family physicians whose productivity falls threaten to be replaced by the physician's assistant and the nurse practitioner, who can provide the triage function far more cheaply. We can expect a concomitant effort to expand the legal prescribing privileges of those less-expensive personnel to accommodate the economics of 21 st century medicine. Furthermore, we can anticipate direct referrals by midlevel practitioners to subspecialists, skipping both the internist and the family physician.

In the 21 st century, the generalist's functions will be so seriously threatened by economic and commercial pressures that they could become either impossible to perform or extinct. This will be tragic to patient care, because the complexity of medicine will increase the need for generalists in direct proportion to their scarcity. It detracts not at all from the great contribution of specialists to recognize that without the generalist there is an enormous hiatus in health care.

We have all encountered patients, friends, or family members whose most urgent need is for someone who can put it all together, who can counsel them through the intricacies of modern medicine. We all know those who have seen the specialist and had the tests but are still confused about their diagnoses, what they should do about them, and how their disease is to be fitted into their lives. As more people live longer and acquire multiple chronic diseases simultaneously or serially, sooner or later everyone will be asked to make choices and benefit-and-burden decisions. We will all face decisions about dying and palliative or hospice care. The need for physicians who can help to discern the right and good thing to do is certain to increase exponentially.

As empirical studies show, patients do not want to make decisions alone. No matter how educated, motivated, or sophisticated they may be, they want to be informed, consulted, and helped. ${ }^{4}$ Given the vulnerability that accompanies illness, the availabil- 
ity of a humane generalist is a necessity for which no specialist can substitute.

Things are not beyond their control, as so many physicians too readily conclude. Physicians still have enormous power, but it is moral power. That power rests in what the loss of the generalist does to patient care, not what is done to the physician's prerogatives. This is the case internists and family physicians should make together. If their plea is genuinely motivated by the patient's interests and not their own, internists and family physicians have a good chance to prevail.

This entails reversal of the slide to deprofessionalization. This is a moral challenge, not a political problem, as too many physicians and professional associations assume..$^{5}$ Physicians will have to recover the moral center of their enterprise, put the primacy of the patient's welfare first, and practice some degree of effacement of self-interest. They will also need to avoid the temptation to retaliate by forming unions, becoming owners and insurers, or hoping to reform managed care by bringing more physicians into its administration.

If the generalist, whether the family physician or the internist, wishes to survive, family medicine and internal medicine must join forces. The distinction between them is difficult for the public to appreciate. Some fusion of their efforts, and even their identities, seems necessary, or both might not survive the next century.

Edmund D. Pellegrino, MD Georgetown University Medical Center Washington, DC

\section{References}

1. Osler W. Aequanimitas, with other addresses to medical students, nurses and practitioners of medicine. Philadelphia: Blakiston, 1932.

2. Pantilat SZ, Alpers A, Wachter RM. A new doctor in the house: ethical issues in hospitalist systems. JAMA 1999;282:171-4.

3. Geyman JP. Family practice: foundation of changing health care. New York: Appleton-Century-Crofts, 1980.

4. Schneider CE. The practice of autonomy: patients, doctors and medical decisions. New York: Oxford University Press, 1998.

5. Pellegrino ED, Relman AS. Professional medical associations: ethical and practical guidelines. JAMA 1999;282:984-6. 